\title{
Is logic distinctively normative?
}

"Like ethics," Frege writes, "logic can [...] be characterized as a normative science." (Frege 1979, p. 128) While contemporary authors seem to find putting logic on a par with ethics going too far, they nevertheless generally agree that the discipline deserves the label "normative", and that this is due to the fact that it somehow is concerned with how we ought to reason (see e.g. Resnik 1985; MacFarlane 2004; Beall \& Restall 2006, p. 16-7; Priest 2006, ch. 11; Taschek 2008; Field 2009a, 2015; Steinberger 2018). ${ }^{1}$

The normative status of $\operatorname{logic}^{2}$ is worth discussing in its own right, but it also has implications for other philosophical debates. Logic's alleged normativity has been taken to spell serious trouble for logical pluralism, which is, roughly, the view that there are different, yet equally correct logical theories. ${ }^{3}$ Taking logic to be normative could also make it harder to defend the view that logic is an objective or realist discipline, in the sense that logical facts obtain independently of the beliefs and practices of human beings. ${ }^{4}$ As is well known from metaethics, the notion of objective normative facts seems to involve something of a metaphysical and epistemological mystery. ${ }^{5}$ On the other hand, if we do take logic to be both normative and objective, the prospects of realism in ethics (and other normative disciplines) seem notably brighter. Confronted with the accusation that they are postulating unacceptably queer entities, ethical realists could point to logic as a highly respectable partner in guilt. ${ }^{6}$

The debate on the normativity of logic has generally focused more on the nature of logic than on the nature of normativity. In this paper, however, I will primarily be discussing what it could mean for logic to be (or fail to be) normative. I will begin by distinguishing between two importantly different claims:

$\mathbf{N}$ : There is a way in which logic is normative. 
D: Logic is normative in a distinctive way, not just in a way that most or all intellectual disciplines are normative.

All the authors who say that logic is normative are obviously committed to N. Somewhat surprisingly, perhaps, none of them explicitly discusses D. Some come very close to endorsing it. For instance, when Frege says that logic is normative "like ethics", it is clear that he would not want to add "and, for that matter, any other discipline." (see Frege 1979; see also Taschek 2008, sect. 3). In other cases, it is hard to tell from the direct textual evidence whether $\mathbf{D}$ or just $\mathbf{N}$ is being defended. However, it is common to characterize most sciences as purely descriptive, so $\mathbf{D}$ is a very natural interpretation of the claim that logic is normative. One would expect authors who do not want to commit to $\mathbf{D}$ to warn us against this possible misinterpretation. The fact that we find no such warnings suggests that those who argue that logic is normative tend to accept, or at least not reject, D. Thus, even if it is hard to assess precisely how plausible it is generally considered to be, $\mathbf{D}$ emerges from the literature as a thesis that is worth taking seriously.

I will argue that $\mathbf{D}$ is false. In the context of normativity, there is nothing special about logic that sets it apart from, say, physics or psychology. I will proceed by examining the various reasons that have been offered in the literature for characterizing logic as normative. More precisely, I will devote one section to each of the following claims:

(1) Logic is not descriptive psychology.

(2) Logic provides norms of belief.

(3) Logic is the science of truth.

(4) Logical laws are constitutive norms for thought.

(5) Logic is a source of requirements of rationality. 
(6) The concept of logical validity is a normative concept.

I will argue that, depending on precisely how they are to be understood, these claims are either plausible but not strong enough to support $\mathbf{D}$, or strong enough to support $\mathbf{D}$ but not plausible.

\section{Logic and descriptive psychology}

At least since Frege, it has been commonplace to distinguish between logic and psychology (see e.g. Frege 1979, p. 142-149; Resnik 1985). When we say that an argument is logically valid, we are typically not making a claim about how people as a matter of fact do argue. To be sure, the psychological fact that most people (or most experts) are prepared to make a certain argument may provide some evidence that it is valid. But that does not mean that what we take it as evidence of is simply that the people in question are likely to make the argument again in the future. We typically take it as evidence that it has the distinct, non-psychological property of being logically valid.

Let us assume that logic is, in this sense, independent of descriptive psychology. Michael D. Resnik takes this thesis to imply that logic is "fundamentally normative" (Resnik 1985, p. 237). His line of reasoning seems to be that if logic isn't about how we do argue, it must be about how we ought to argue (see also Priest 2006, p. 176). But this is a false dichotomy. Logic could be non-psychological, yet non-normative. It could have its own facts to describe.

What would such descriptive logical facts be? Specifying precisely what logic is about is no easy task, but part of the answer is surely that it identifies possible and impossible patterns of truth values in sentences. ${ }^{7}$ Take, for instance, the notion of validity. Valid arguments are standardly understood as arguments with a logical form that makes them truth- 
preserving: if the premises are true, so is, necessarily, the conclusion. ${ }^{8}$ Whether an argument is truth-preserving is clearly a factual or descriptive question, even though it isn't a psychological question. Thus, when a classical logician declares disjunctive syllogisms to be valid, what he has in mind need not be that most people infer $q$ from $p$ or $q$ and not $p$, or that they are under some sort of normative obligation to do so. He could simply be saying that $q$ must be true if $p$ or $q$ and not $p$ are both true.

Similarly, a set of sentences is said to be inconsistent if and only if it is logically impossible for all the sentences to be true, or if and only if it entails a sentence as well as its negation. ${ }^{9}$ Logical truths can be defined as sentences with a logical form that makes them necessarily true. These definitions are neither psychological nor normative.

Of course, it may be that discovering descriptive facts about truth value patterns is not the only thing logicians are doing. Moreover, there might be normative facts supervening on these descriptive facts, or implied by them when combined with plausible normative assumptions. My present point - which is generally accepted even by the authors who think that logic is normative (see e.g. Frege 1918, p. 58; MacFarlane 2002; Taschek 2008; Field 2015) - is merely that non-psychological logic at least has a descriptive side. This means that one cannot establish any conclusions about the normativity of logic simply by arguing that logic is not psychology.

\section{Logical norms of belief}

Even if logical relations such as entailment and inconsistency can be described in nonnormative terms, they could at the same time be relevant for what we ought to believe. Some authors take the normative aspect of logic to consist precisely in being a source of norms of belief (MacFarlane 2004; Field 2015; Steinberger 2018; see also Steinberger 2017). 
A complication for this approach is that logicians normally take entailment and consistency to be relations between sentences in a formal language, not between psychological states such as beliefs. Moreover, arguments are not the same thing as inferences, understood as psychological processes that can result in new or revised beliefs. Nevertheless, it seems plausible to assume that at least some beliefs can be expressed by sentences in a formal language, and that there is therefore a sense in which beliefs can entail other beliefs, and in which inferences can be valid. At any rate, I will, in the following, talk about logical relations obtaining between beliefs (and sometimes also propositions), and about inferences being logically valid or invalid.

\section{$\underline{2.1 \text { Some logical norms of belief }}$}

In this section, I present the standard candidates for logical norms of belief (in a fairly simple form; I will address some complications in section 2.3). Here is one of them:

I: One ought not to have logically inconsistent beliefs.

Since the premises of a valid argument and the negation of its conclusion form an inconsistent set, I forbids us from believing in the premises of a valid argument and disbelieving the conclusion. Believing the premises and suspending judgment on the conclusion would, on the other hand, not be a violation of the requirement. However, there is clearly something wrong with such a pattern of doxastic attitudes. We thus need another principle:

V: One ought not to believe in the premises of a valid argument and at the same time refrain from believing in the conclusion. ${ }^{10}$ 
For instance, you should not believe $p$ and if $p$ then $q$ while failing to believe $q$.

If you do find yourself in a situation where you believe in the premises of an argument without believing the conclusion, $\mathbf{V}$ does not tell you which doxastic attitude you ought to change. You could stop believing in at least one premise, start believing in the conclusion, or both. All V tells you is that your present state is not acceptable.

A tacit assumption behind $\mathbf{I}$ and $\mathbf{V}$ is that belief is an all-or-nothing affair. When we are faced with a proposition, we either fully believe it, fully disbelieve it or suspend judgment completely. However, there clearly are degrees of belief. We can have more or less credence in a proposition. It is common to place credences on a scale ranging from 0 (full disbelief) to 1 (full belief). When credences between 0 and 1 are involved, the question of how to respond to valid arguments or inconsistency becomes more complicated. There is nothing wrong with having some credence in each member of a set of inconsistent propositions. If you, for instance, have 0,5 credence in $p$, you could (and on some logics always should) have 0,5 credence in not $p$. If the set of inconsistent beliefs is very large, as in the lottery paradox, you could rationally have a very high degree of credence in each individual member.

Moreover, there is no general norm specifying exactly which credence you should have in the conclusion of a valid argument if your credences in the premises are less than 1. We can, however, formulate a general minimal requirement. Let us call one's credence in a proposition $c$. One's degree of disbelief in a proposition can then be defined as (1-c). Building on probability theory, we can say that one's degree of disbelief in the conjunction of the premises should not exceed the sum of one's degree of disbelief in each premise. Since we should not be more skeptical of the conclusion of a valid argument than we are towards the conjunction of its premises, we obtain the following principle: 
V+: One ought not to be in a state where one's degree of disbelief in the conclusion of a valid argument exceeds the sum of one's degree of disbelief in its individual premises. ${ }^{11}$

Let's say that you have a credence of 0,75 in $p$ and, and the same credence in if $p$ then $q$. It follows from $\mathbf{V}+$ that you should not at the same time have a credence in $q$ of less than 0,5 . Since uncertainties quickly add up, $\mathbf{V}+$ does not always provide useful guidance. Let's say your credence in if $q$ then $r$ and in if $r$ then $s$ is also 0,75 . Now you only know that your uncertainty in should not exceed 1, which is not very helpful.

$\mathbf{V}$ is in fact just a special case of $\mathbf{V +}$. If one's credence in each premise is 1 , the sum of the degrees of disbelief is 0 , and so any degree of disbelief in the conclusion above 0 is unacceptable. This is just another way of saying that one should not fully believe the premises of a valid argument without fully believing in the conclusion.

\subsection{Why obey these logical norms of belief?}

Let us, at least for now, assume that $\mathbf{I}, \mathbf{V}$ and $\mathbf{V}+$ are correct norms of belief. In order to assess how this affects the normative status of logic, we need to examine the normative status of the principles themselves. A good way of doing so is to ask why one should follow them. The answer I will provide is that these norms follow from more general norms of belief. ${ }^{12}$ I begin with a simple version of this answer and discuss some complications in the next section.

We can explain what is wrong with violating $\mathbf{I}$ by appealing to the normative principle that one ought not to believe what is not true. Necessarily, at least one of a set of inconsistent propositions fails to be true. Hence, believing in all of them necessarily involves believing something that isn't true. 
As regards $\mathbf{V}$, either the premises of a valid argument are all true, or at least one of them is false. If at least one of the premises is false, believing in all of them violates the norm that one should not believe what is not true. If they are all true, the conclusion is also true, and failing to believe it involves failing to believe what is true. This violates the norm that one ought to believe what is true. Thus, no matter what the actual truth values of the premises are, there is something wrong with the doxastic attitudes of a person who fails to satisfy $\mathbf{V}$.

$\mathbf{V}+$ can be justified by the normative principle that one's degree of disbelief in a proposition ought to correspond to its probability of being false. This can be seen as the flip side of the principle that one's credence in a proposition ought to correspond to its probability of being true. ${ }^{13}$ Probability theory tells us that the probability that the conclusion of a valid argument is false cannot exceed the sum of each premise's probability of being false. ${ }^{14}$ This means that if one's degree of disbelief in the conclusion exceeds the sum of one's degree of disbelief in each premise, at least one degree of disbelief must fail to correspond to the actual probability of falsity. If one has the right degree of disbelief in the conclusion, there is too little disbelief in at least one premise. If one has the right degree of disbelief in the premises, there is too much disbelief in the conclusion. It is thus only by obeying $\mathbf{V}+$ that we have a chance of getting all our credence levels right.

\section{$\underline{2.3 \text { Some complications }}$}

In a complete account, $\mathbf{I}, \mathbf{V}$ and $\mathbf{V +}$, as well as the general norms of belief I have appealed to, would presumably need to be formulated more carefully. It is not necessary for my purposes to take a stand on precisely how this should be done. I will, nevertheless, mention some of the complications, just to show that they do not threaten the basic idea that logical norms of belief can be derived from more general norms of belief. 
It is clearly impossible for human beings to believe everything that is true and nothing else. Also, some beliefs are presumably more important to get right than others. A simple injunction to believe what is true and only what is true therefore seems unsatisfactory. However, this does not give us any reason for doubting whether logical norms of belief can be derived from more general norms of belief, since there is the same apparent need to qualify $\mathbf{I}$, $\mathbf{V}$ and $\mathbf{V}+$. For instance, as Gilbert Harman notes, one cannot believe fully in every logical consequence of one's full beliefs, and many such consequences are utterly trivial and hence pretty pointless to believe in any case (Harman 1986, ch. 2). ${ }^{15}$ I see no reason to expect a divergence between the kind of qualifications that seem reasonable on the level of logical norms of belief and those that do so on the general level.

Complications also arise if we take inconsistency to consist in entailing a proposition and its negation and at the same time accept the dialetheist view that a proposition and its negation can both be true. On these assumptions, we sometimes need to be inconsistent in order to believe what is true, which would make it difficult to defend I on the basis of general norms of belief. However, this is presumably as it should be, since the authors who accept these assumptions do not support a general ban on inconsistency in any case (see e.g. Priest 2006).

A further question is whether we should construe the obligation to believe what is true and only what is true in a consequentialist way, where the ultimate goal is to maximize (something like) the total number of true beliefs minus the total number of false beliefs. On this view, whether we ought to believe in a given proposition depends not only on whether it is true, but also on the truth values of any resulting beliefs. In a case where forming a false belief somehow causes a large number of true beliefs, we ought to form the false belief. ${ }^{16}$ Here, too, it seems that one's general attitudes would be mirrored on the level of logical norms of belief. Those who otherwise find epistemic consequentialism plausible will be 
happy with a consequentialist understanding of logical norms of belief - where, for instance, we ought to be inconsistent in the cases where that brings about the best available total pattern of doxastic attitudes. Conversely, those who reject consequentialism as a general doctrine will see no need to defend consequentialist versions of $\mathbf{I}, \mathbf{V}$ or $\mathbf{V}+$.

Finally, it is not clear what sort of theoretical status we should accord to the general norms of belief I have appealed to. Truth is widely considered to be the most fundamental aim or value in epistemology (see e.g. Wedgwood 2002, Sylvan 2018), but perhaps what we really should seek is something more complicated that merely involves truth, such as for instance knowledge. Moreover, seeking truth or knowledge could be understood as an ethical obligation rather than (or as well as) an epistemological obligation (see e.g. Papineau 1999). Knowledge is a standard candidate for intrinsic ethical value, and true beliefs have significant instrumental value on any reasonable ethical outlook. Once more, it seems that however we resolve these issues, we could still derive our favored logical norms of belief from more general norms that have nothing in particular to do with logic.

\subsection{Does this account make logic distinctively normative?}

If the normative explanation I have provided is correct, we get the following picture. Logic makes descriptive claims about the formal relations between the truth values of different beliefs. We only obtain logical norms of belief such as $\mathbf{I}, \mathbf{V}$ and $\mathbf{V}+$ if we combine these descriptive claims with general norms of belief. Had we not been under any obligation to avoid untruth, for instance, we would not be under any obligation to have logically consistent beliefs, either. Logic is thus only normative in a derivative way. It helps us to have the right doxastic attitudes.

Derivative normativity is of course still normativity. Graham Priest presents the claim that we ought to reason validly because doing so helps us achieve our epistemic goals as an 
explication of the idea that logic is normative, and not a debunking of it (Priest 2006, p. 191192). However, if we want to say that this kind of doxastic usefulness is sufficient to make logic a normative discipline, it is hard to see how any intellectual discipline could fail to be normative. After all, any such discipline will tell us something about what is true, false or probable, which in turn is relevant for what we ought to believe. For instance, physics enables us to say that one ought to believe that any two objects with mass will attract one another. Psychologists tell us that we should not expect people to be particularly good at reasoning with probabilities. Logic may of course be special in being more general than the other disciplines, and in forming a necessary part of them. That would give the logical norms of belief a uniquely wide scope, but we would still be talking about the same kind of normativity that is found in all areas of inquiry.

We thus have a choice. We can either say that the existence of logical norms of belief fails to make logic a normative discipline, or we can say that any intellectual activity that helps us believe what is true and only what is true is normative. As long as we make it clear how we use our terms, it may not matter much which option we choose. The important point is that, on the account I have presented, the existence of logical norms of belief would not make logic normative in any special way.

I have not shown conclusively that this account is correct, of course. However, it clearly has some plausibility. Though the details are a tricky matter, I find it hard to see how there could be no sense whatsoever in which we ought to believe what is true, not believe what is not true, and have our degree of disbelief in propositions correspond to their likelihood of being false. If there are such general norms of belief, that is enough for logical norms of belief to obtain, and the defenders of logical norms of belief have not offered any alternative accounts of their normative basis. ${ }^{17}$ For these reasons, I think it is fair to say that 
the burden of proof in on those who might want to claim that logical norms of belief provide logic with a distinctive normative status.

\section{Logic as the science of truth}

As we have seen, helping us to form true beliefs does not make logic normatively special. However, logic not only aims at truth; it theorizes about it in a much more direct way than what we find in (most) other disciplines. Frege, in the passage I began this paper by quoting, seems to claim that this is what makes logic a normative discipline. After observing that "all the sciences have truth as their goal", he points out that logic is "concerned with the predicate 'true' in a quite special way, namely in a way analogous to that in which physics has to do with the predicates 'heavy' and 'warm'.” (Frege 1979, p. 128) But whereas heaviness and warmth clearly are purely descriptive properties, truth is, as we have already seen, something that we apparently ought to seek. Frege thus thinks we can say that truth is the subject matter of logic in the same way that goodness is for the clearly distinctively normative discipline ethics (and in the same way that beauty is for aesthetics).

How, precisely, are we to understand this analogy between logic and ethics? Frege does not provide much elaboration, but he does say that logic answers the question: "How must I think in order to reach the goal, truth?" (Frege 1979, p. 128) Perhaps his idea is that ethics, similarly, attempts to answer the question: How must I act in order to reach the goal, goodness? But surely the basic ethical question involving goodness is simply: What is good? Once we know what is good, we do not need any further normative knowledge in order to figure out how to reach it. A form of ethics that takes some conception of the good to be externally established and only studies how to realize it would only be normative in a derivative way - as would a form of logic that takes the obligation to seek truth to be externally given and only tells us something about how to discharge it. 
Presumably, though, Frege takes logic to deal with the goal of truth itself, and not just the means to reach it. We need to distinguish between two ways in which it might do so. First, logic could tell us something about the nature of truth. Frege is skeptical about the possibility of a reductive analysis (see e.g Frege 1979, p. 128-129), but even if the notion of truth has to be taken as primitive, we could arguably gain a deeper understanding of it by studying the role it plays in logical theories. However, being the science of truth in this sense would not make logic distinctively normative. All sorts of disciplines study descriptive properties of things that we also take to have normative properties. For instance, psychology is (among other things) the science of pleasure, but not even a hedonist would want to claim that it is thereby a distinctively normative discipline. Psychologists only tell us what pleasure is and what it does; whether it is something we ought to seek is a question for moral philosophers. ${ }^{18}$

Thus, for logic to be distinctively normative, it is not enough that it theorizes about truth and that truth is something we ought to seek. It would have to study the value of truth directly; the principle that one ought to seek truth must itself be a logical principle. Whether this condition is satisfied depends on what we mean by "logic". Here are two possible definitions:

L1: Logic is the study of validity (and related properties such as logical truth, consistency, soundness and completeness).

L2: Logic is the study of validity and all other aspects of truth.

$\mathbf{L}_{\mathbf{2}}$ allows us to say that logic studies the value of truth, whereas $\mathbf{L}_{\mathbf{1}}$ does not. One can specify which arguments are truth-preserving without making any claims about the goodness of truth or the badness of untruth. Of course, one's aim will be to say something true about validity, so even on $\mathbf{L}_{1}$ logicians must be committed to the value of truth. But as Frege notes, any 
scientist must have this commitment. $\mathbf{L}_{\mathbf{1}}$ does not yield any special relationship between logic and the value of truth.

Frege may have proceeded on something like L2. It might not be an unreasonable definition of logic, but it does not fit modern usage. At least as far as the debate about the normative status of logic is concerned, contemporary definitions of logic provided are all along the lines of $\mathbf{L}_{\mathbf{1}}$ (Resnik 1985; Harman 1986, ch. 1-2; Priest 2006, p. 176; Beall \& Restall 2006, p. 3; Russell 2017, sect. 2, Steinberger 2017, sect. 1). Thus, arguing that logic has a special normative status based on $\mathbf{L}_{2}$ would simply be changing the subject. The debate is not about whether we should begin (or resume) using the word "logic" in a way that makes the value of truth a logical entity. It is about the normative status of the activity in $\mathbf{L}_{\mathbf{1}}$.

\section{Constitutive norms for thought}

Several interpreters take Frege to hold a different (or possibly supplementary) thesis on the normativity of logic, namely that logical laws are constitutive norms for thinking. According to this thesis, if you fail to be appropriately governed by logical laws, the problem is not simply that your thinking will produce the wrong doxastic attitudes. Rather, what you are doing will not even count as thinking in the first place.

In this section, I examine some possible constitutive norms for thought. I will argue that they are either too weak to support $\mathbf{D}$ or too strong to be plausible. I begin with the following candidate:

C1: We only count an activity as thinking if it conforms to $\mathbf{I}$ and $\mathbf{V} \cdot{ }^{19}$

One questionable implication of this principle is that logically flawed thinking is impossible: to the extent that we make logical mistakes, what we are doing no longer counts as thinking. 
But let us assume that this is not a problem. $\mathbf{C}_{\mathbf{1}}$ is not in itself a normative principle. It simply gives us a (partial) description of what thinking is. Similarly, we might say that we only count an activity as flying if it conforms to the rule "don't touch the ground". Clearly that does not commit us to the normative principle that one ought to stay away from the ground, or to taking the study of flight to be a normative enterprise. Of course, one might plausibly think that we ought to be thinkers in a way that we are not obliged to be flyers. But why? Here, we can once more appeal to the general norms of belief: we ought to think, which includes obeying $\mathbf{I}$ and $\mathbf{V}$, because we ought to have the right doxastic attitudes. If we otherwise find this a reasonable answer, $\mathbf{C}_{\mathbf{1}}$ by itself does not give us any reason to change our mind.

Here is a more explicitly normative principle:

C2: We only count an activity as thinking if it ought to conform with $\mathbf{I}$ and $\mathbf{V} .{ }^{20}$

This principle does not say why thinking ought to conform with I and V. We could say that C2 obtains because:

C3: We only count an activity as thinking if it involves an obligation to believe what is true and only what is true.

This explanation in terms of more general norms seems no less plausible in the case of logical constitutive norms of thought than in the case of logical norms of belief. Now even if the logical constitutive norms are derivative, their existence would still provide logic with a form of normativity that goes beyond the one discussed in section 2. However, this would not support $\mathbf{D}$, since other disciplines also yield constitutive norms for thought when combined with C3. For instance, as John MacFarlane observes, we would not count an activity as 
thinking about the physical world unless it is somehow "assessable in light of the laws of physics" (MacFarlane 2002, p. 37). To be sure, other disciplines only provide constitutive norms for thinking about specific domains (for instance the physical world) and not for thinking as such, but that is a reflection of the fact that logic is distinctively general, not that it is distinctively normative.

$\mathbf{C}_{1}-\mathbf{C}_{3}$ are silent on the normative commitments of the thinker himself. According to William W. Taschek, Frege requires that a thinker must acknowledge the authority of logic. This gives logic a special normative status, since no other disciplines provide constitutive norms of thinking of this kind (Taschek 2008). ${ }^{21}$ For instance, there is no physical law such that one cannot even think about the physical world without acknowledging its authority (Taschek 2008, sect. 3). Before drawing this conclusion, however, we need to have a closer look at what sort of normativity authority thinkers might have to accord to logic.

Here is one possible principle:

C4: In order to count as a thinker, one must acknowledge an obligation to obey $\mathbf{I}$ and $\mathbf{V}$.

In addition to the right general attitude towards logical inconsistency and validity, we might want to require a normative commitment to more specific laws of logic. For instance:

C5: In order to count as a thinker, one must acknowledge an obligation not to believe $p$ and not $p$ at the same time.

C6: In order to count as a thinker, one must acknowledge an obligation to believe $q$ if one believes $p$ and if $p$ then $q$. 
It is far from obvious that we should accept these principles. Being a thinker does seem to require a disposition to form beliefs in a way that to some minimal degree coincides with what $\mathbf{I}$ and $\mathbf{V}$ demand. However, this does not mean that any normative beliefs or feelings of obligation must be involved. I doubt that all the human beings we would want to classify as thinkers have a clearly normative commitment to logic. Even if they do, this may not be what makes them thinkers. Imagine, for instance, a supremely intelligent creature that nearly always forms the right doxastic attitudes. However, it does not believe or feel that its mind ought to comply with $\mathbf{I}$ and $\mathbf{V}$; it just has a mind that does. It does not seem unreasonable to classify this creature as a thinker.

One way of motivating $\mathbf{C}_{4}-\mathbf{C}_{6}$ is to appeal to something like:

C7: In order to count as a thinker, one must acknowledge an obligation to believe what is true and only what is true.

C8: In order to count as a thinker, one must have a basic understanding of logical laws and concepts.

By satisfying these requirements, one would, it seems, also satisfy the requirements in $\mathbf{C}_{4}$ - $\mathbf{C}_{6}$. $\mathbf{C}_{7}$ and $\mathbf{C} 8$ can of course also be questioned. However, the important point for my purposes is that if we justify $\mathbf{C}_{\mathbf{4}}-\mathbf{C}_{\mathbf{6}}$ in this way, it would be misleading to say that thinkers need to have a special normative commitment to logic. The real difference between logic and other disciplines is that thinkers need to understand a bit of logic, whereas they can be ignorant about all other disciplines. Thus, for constitutive norms like $\mathbf{C}_{4}-\mathbf{C}_{6}$ to provide support for $\mathbf{D}$, they would have to be defended in some other way.

Taschek's formulation of the thesis that logic provides constitutive norms for thought is actually somewhat stronger than the ones I have provided above. He suggests that in order 
to be a thinker, one must acknowledge "the categorical normative authority that logic has over one's practice of judging, asserting, and inferring." (Taschek 2008, p. 384 (emphasis added)); see also Mezzadri 2015, p. 598). Moreover, acknowledging this authority involves feeling an "unconditional" obligation to correct logical mistakes (Taschek 2008, p. 384; see also Steinberger 2017, sect. 2.2). Taschek himself does not put much stress on these additional requirements; he does not explain why he believes that thinkers must accord logic categorical and unconditional authority, or even precisely what doing so involves. However, given how these terms are normally used, we could reasonably take him to suggest principles such as:

C9: In order to count as a thinker, one must acknowledge an attitude-independent obligation to obey $\mathbf{I}$ and $\mathbf{V}$.

C10: In order to count as a thinker, one must acknowledge a non-derivative obligation to obey $\mathbf{I}$ and $\mathbf{V}$.

C11: In order to count as a thinker, one must acknowledge an overriding obligation to obey I and $\mathbf{V}$.

Logic may have a special normative status if any of these principles are correct (this would at least appear to be the case for $\mathbf{C}_{\mathbf{1 0}}$ ). However, they are all highly implausible. One does not lose one's status as a thinker by coming to believe that the reason to obey $\mathbf{I}$ and $\mathbf{V}$ ultimately derives from one's desires or from general norms of belief, or that this reason could be outweighed by other reasons. (If one did, there must be quite a few non-thinking philosophers around.) Of course, for all I have said in this section, the normative authority of $\mathbf{I}$ and $\mathbf{V}$ may well be both attitude-independent, overriding and non-derivative. The point is just that one does not need to believe that it is in order to be a thinker. 
I conclude that the candidates for logical constitutive norms of thinking that have been suggested in the literature either fail to be convincing or fail to entail $\mathbf{D}$.

\section{Logic and rationality}

There is wide agreement that logic is a source of requirements of rationality. One may not need to comply with $\mathbf{I}$ and $\mathbf{V}$ in all cases to count as a rational person, but it seems one must at least do so when faced with obvious instances of inconsistency or entailment. Here are two candidates for logical requirements of rationality formulated by John Broome:

Rationality requires of $N$ that $N$ does not believe at $t$ that $p$ and also believe at $t$ that not $p$. (Broome 2013, p. 155; see also Reisner 2011, sect. 5)

Rationality requires of $N$ that, if $N$ believes at $t$ that $p$, and $N$ believes at $t$ that if $p$ then $q$, and if $N$ cares at $t$ whether $q$, then $N$ believes at $t$ that $q$. (Broome 2013, p. 157; see also Kolodny 2005, p. 514-515)

Let us assume that there are logical requirements of rationality of this kind. Does this affect the normative status of logic? The answer obviously depends on the normative status of the rational requirements themselves.

One need not take these requirements to involve any normative claims. They could simply be telling us what is needed to meet the description "rational". Similarly, we could say that being a snob requires despising popular music, without thinking that there is any reason to be a snob or to despise popular music. ${ }^{22}$ One could also take (theoretical) rational requirements to derive their normative authority from an epistemic obligation to believe what is true and only what is true (see Reisner 2011, esp. sect. 5).

Broome, however, thinks that rational requirements have a non-derivative normative force (Broome 2013, ch. 11; see also Berker 2013). That is, the fact that rationality requires us 
to think in accordance with modus ponens and to avoid believing in contradictions is in itself a reason for thinking in accordance with modus ponens and avoiding believing in contradictions. If this view is correct, logic does have a special normative status. After all, most disciplines are not direct sources of rational requirements. (It is not inherently irrational to fail to believe in quantum mechanics, for instance.)

Broome admits that he does not have a convincing argument for the non-derivative normativity of rationality. He is thus forced to take is as a brute normative fact (Broome 2013, p. 204). For this view to be plausible, a minimum requirement is that we have clear grasp of what it is that is supposed to have the brute and non-derivative normative force. At least when it comes to the kind of rationality that involves logic, I find this grasp elusive. We cannot say that being logically rational just is following the individual rational requirements involving logic. If we did, we could not appeal to the notion of rationality in an explanation of the normative authority of the individual requirements. It would be pointless to say that we should, at least in certain instances, obey $\mathbf{I}$ and $\mathbf{V}$ because doing so is rational, if being (logically) rational only amounts to obeying $\mathbf{I}$ and $\mathbf{V}$ in the very same instances. The framework of rationality has to be something over and above the individual requirements to which it is supposed to accord normative authority. But what, exactly? We could provide an informative general characterization of theoretical rationality by saying that it is concerned with the pursuit of truth or knowledge. But that would presumably make the normative authority of logical rational requirements dependent on this aim, and the concept of rationality once more becomes explanatorily superfluous.

It seems, then, that appealing to rationality fails to provide logic with additional normative authority. Instead of saying that we should obey $\mathbf{I}$ and $\mathbf{V}$ because doing so is rational and we just should be rational, one might as well say, more directly, that we just 
should follow $\mathbf{I}$ and $\mathbf{V}$ - that is, that the logical norms of belief themselves have some kind of non-derivative normative force. I will return to this possibility in section 7.

\section{A normative concept of logical validity}

Until now, I have assumed that logically valid arguments are characterized by having the descriptive property of being truth-preserving. Hartry Field argues that while this conception of validity is satisfactory for arguments with "ordinary" premises, it breaks down in other cases. Unless we restrict the scope of our logical theory to an unacceptably high degree, we cannot consistently say that all the arguments we take to be valid are truth-preserving. We end up declaring some inferences we actually accept as invalid, or classifying as valid inferences that we actually reject (Field 2015, sect. 1; see also Field 2009a; Field 2009b). Field's argument involves various possible responses to logical paradoxes. I will neither present nor evaluate it here. ${ }^{23}$ For the sake of argument, I will assume that he is right.

Field's preferred alternative is a normative conception of validity, where regarding an argument as valid essentially involves accepting the normative constraint on one's beliefs posited by $\mathbf{V}+$. To be sure, Field does not think that validity has nothing whatsoever to do with preserving truth. He accepts the coextension of truth-preservation and validity for all arguments with "ordinary" sentences. Moreover, we should not accept the constraint in V+ for any arguments where there is a "clear" case of failure to preserve truth (Field 2015, sect. 1). Thus, facts about truth-preservation narrow down the list of possible logics, and may allow us to say that some of these logics are, on the whole, preferable to others. But to the extent that they fail to do this, the choice between different logics is "irreducibly a matter of normative policy.” (Field 2015, p. 61; see also Field 2009b, p. 358-359)

Clearly, Field's normative conception of validity does not follow directly from the absence of a satisfactory general truth-preservation account ("Now there is a real 
nonsequitur!" Gilbert Harman exclaims after attributing such a line of reasoning to Field (Harman 2009, 335)). Instead of concluding that validity is something else than truthpreservation, we could conclude that we simply cannot say whether arguments with certain kinds of non-ordinary premises are valid, since there is no acceptable consistent answer to the question of whether they preserve truth. This would no doubt be a disappointment for logicians, but it would presumably not affect the use of logic in other disciplines, where we only need ordinary premises.

In other words, we need some reason for thinking that when we cannot say whether an argument is truth-preserving, we can still make judgments about its validity on the basis of V+. Why would we be forbidden from fully believing in the premises and failing to fully believe in the conclusion unless it is a fact that the conclusion must be true if the premises are true? Field's answer (and the only promising answer I can think of) is that $\mathbf{V}+$ applies in such cases because we make it apply. More precisely, he proceeds on an expressivist understanding of normativity: a judgement that an argument is valid expresses (or projects) one's commitment to adopt the policy of V+ towards it (Field 2009b, §7-8; Field 2015, sect. 4). This means, in effect, that we can (within the limits mentioned above) make an argument valid (for ourselves, at least) by deciding not to have our degree of disbelief in its conclusion exceed the sum of our degrees of disbelief in each premise.

The expressivist analysis of normativity is of course controversial. Many moral philosophers deny that we can have a normative reason to do something that ultimately derives from the fact that we are, in some way, in favor of doing it. Even if one finds expressivism convincing in ethics, one might wonder about whether it is equally plausible when applied to logic. Whereas all normal human beings more or less automatically form strong ethical attitudes that expressivists can rely on in their theorizing, the kind of normative commitment Field is talking about seems a bit more peculiar. Keep in mind that the cases 
where he thinks it is called for are highly theoretical. We do not need to adopt a policy about them in order to get by in everyday life. If it really is the case that none of the possible logical policies are objectively preferable, it seems quite natural and reasonable to adopt an attitude of agnosticism. I, for one, would find it difficult to adopt the constraints of $\mathbf{V}+$ wholeheartedly in such a situation. ${ }^{24}$

However, let us disregard these worries and accept Field's account of validity. Since validity is a central logical concept, to the point that the entire discipline is often defined in terms of it, this might seem to make logic distinctively normative. However, what Field's analysis of validity in the end boils down to, is the claim that we can maintain a doxastic commitment to a logical theory even if it isn't uniquely supported by the descriptive facts. Presumably, we can do something equivalent in any discipline where theory choice is underdetermined by our descriptive knowledge. You might, say, embrace your favorite macroeconomic theory or your favorite interpretation of quantum mechanics. And if this kind of commitment constitutes or generates normativity in logic, it is hard to see why it would not do in the other cases as well. You could say that you ought to believe in Bohm's version of quantum mechanics, for instance, where this simply expresses your commitment to believe in it. In this sense, the physical question of how to interpret quantum mechanics turns out to be in part a normative question. Once more, what (arguably) makes logic normative is not peculiar to logic.

\section{Brute normative facts?}

I have examined the various suggested explanations of what makes logic normative and argued that, to the extent that these explanations are plausible, they also apply to other intellectual disciplines. However, it is widely accepted that normative explanations have to end somewhere, and that one can therefore sometimes legitimately appeal to brute normative 
facts. Thus, we sometimes find moral philosophers insisting that pain just is bad (e.g. Nagel 1986, p. 156-162), or that we just should be moral (e.g. Prichard 1912). One could, similarly, claim that logic is normative in a brute, non-derivative way that resists explanation. For instance, there might just be something inherently and importantly wrong with a person who doesn't care that he is inconsistent, beyond the fact that at least one of his beliefs will fail to be true.

If this view is correct, logic clearly has a distinctive normative status. But is there any reason to think that it is? One way of trying to justify it would be to appeal to the way we talk about logic. We clearly use non-derivative normative terms more frequently in logical discourse than we do in the case of most other intellectual disciplines. We do not say that valid arguments are good as means to forming true beliefs, or that inconsistency is bad since it involves falsehood. We simply call these things good and bad. However, this is hardly convincing evidence that we take logic to be normative in some non-derivative and special way. We tend to slip into a non-derivative normative vocabulary wherever there is an implicit shared aim. For instance, dieticians tell us that we ought to eat vegetables every day and that we shouldn't have more than $25 \%$ body fat. This is obviously not evidence that they take their discipline to be intrinsically normative. Strictly speaking, all they are doing is describing and causally explaining some of the things that happen in our bodies. They only use a normative vocabulary because they know we all want to be healthy. We should expect the same thing to happen in logic. Truth is an extremely widely shared aim; as we saw in section 4 , we may not even count as thinkers if we fail to have it.

A more common and straightforward way of defending the existence of brute normative facts is to appeal to intuition. I do not think this strategy is likely to succeed in the case of logic. First of all, I suspect that too few philosophers will be inclined to make the required intuitive judgments. As far as I know, such judgments are nowhere to be found in the 
literature (though in part this may of course be attributable to the fact that many authors have been less than clear about the precise sense in which they take logic to be normative). Speaking for myself, I find that after considering all the ways in which logic might be nonbrutely normative, there are no remaining appearances of normativity to be discerned.

Second, I believe that intuitions in favor of the view that logic has a brute normative force, even if they turn out to be reasonably prevalent, would be vulnerable to debunking. Parents and teachers tend not to draw subtle distinctions between derivative and nonderivative logical normativity. They simply require us to be consistent and to draw the logical implications of our existing beliefs, and they blame us when we fail to live up to their standards. Given how the human mind works, this could easily make logic seem normative in its own right even if it isn't.

\section{Conclusion}

We do not have any good reason to think that logic is distinctively normative. Ethical realists might have preferred a different conclusion. But as regards the intellectual standing of logic itself, I do not think we have any reason to be dissatisfied. Even if logic isn't distinctively normative, we can still, if we are so inclined, take logic to be special in other ways, to be objective, and to be highly useful in figuring out what to believe.

\footnotetext{
${ }^{1}$ Two notable skeptics are Gilbert Harman (1986, ch. 2) and Gillian Russell (2017).

${ }^{2}$ By "logic", I mean formal deductive logic, as do the other participants in the debate. I do not think the normative status of this kind of logic differs from that of informal or inductive logic, but I will not pursue this question.

${ }^{3}$ For elaboration and a response, see Caret 2017.

${ }^{4}$ For a more careful formulation of logical realism, see McSweeney 2017.

${ }^{5}$ For a classic statement of some of the metaphysical objections to normative realism, see Mackie 1977.
} 
${ }^{6}$ Some ethical realists pursue an analogous strategy involving a normative conception of epistemology (see e.g. Shafer-Landau 2003, p. 205-6; Cuneo 2007).

${ }^{7}$ For a more detailed account along these lines, see Russell 2017, section 5.

${ }^{8}$ There are different ways of making this notion technically precise. Also, some logicians think that valid arguments must fulfil further (descriptive) conditions, such as relevance. I only assume that being truthpreserving is a necessary condition of being valid. As we will see in section 6 , even this assumption is not universally accepted.

${ }^{9}$ In classical logic, these definitions are of course equivalent.

${ }^{10}$ Principles similar to $\mathbf{I}$ and $\mathbf{V}$ are discussed by Harman (1986) and several later authors.

${ }^{11}$ For a similar principle, see Field 2015. Strictly speaking, we should specify that all the premises must be necessary to derive the conclusion. Otherwise, the required credence in the conclusion can be lowered by adding unnecessary premises in which one does not have full credence (see Adams 1998).

${ }^{12}$ For a similar account, see Russell 2017, sect. 4.

${ }^{13}$ On the not uncommon view that probabilities are reducible to credence levels, this principle might perhaps seem to have no real normative content. However, the idea behind this view is not that all actual credences automatically generate a corresponding probability, but that probabilities are a function of credences that are in some sense rational, which at the very least includes compliance with basic probability theory (for an overview, see Hajek 2012, sect. 3.3). Actual credences therefore can - and presumably often do - differ from true probabilities, which means that a normative requirement of correspondence is not vacuous.

${ }^{14}$ For a proof, see Adams, 1998, p. 38.

${ }^{15}$ For discussions of how logical norms of belief should be modified or qualified in light of Harman's objections, see e.g. MacFarlane 2004; Field 2009a, sect. 1; Steinberger 2018.

${ }^{16}$ For discussion, see e.g. Berker 2013; Singer 2018.

${ }^{17}$ An exception is Hartry Field, whose views I discuss in section 6.

${ }^{18}$ Matters would be more complicated if we take the very nature of truth to be normative: for a proposition to be true just is the obtaining of some normative fact, perhaps that one ought to believe in it. On this view, all disciplines that aim to say something true, which is more or less all disciplines, would be normative in the sense of being directly concerned with what we ought to believe. Logic might then be special in not just discovering obligations of this kind, but telling us something about their nature - though that would seem to make it a part of the metaethics of belief rather than distinctively normative on the first-order level. In any case, any theory of 
truth along these lines would of course be highly controversial. I am not aware of any convincing arguments for accepting such a theory, or of any accounts of the normativity of logic based on one.

${ }^{19}$ James Conant (1991) offers an interpretation of Frege along these lines. V+ is presumably too sophisticated to be a plausible candidate for a constitutive norm of thinking, so I will ignore it in this section. I will also ignore complications of the kind discussed in section 2.3.

${ }^{20}$ This is, roughly, how John MacFarlane (2002) understands Frege's view.

${ }^{21}$ One could object that this line of argument cannot show that logic really is normative, but only that it must be taken to be so by thinkers. However, given that all normal human beings are thinkers whether they want to or not, that might not make too much of a difference.

${ }^{22}$ For an argument that rational requirements are entirely non-normative, see Kolodny 2005.

${ }^{23}$ For a defense of the truth-preservation account of validity against the present form of criticism, see Murzi, \& Shapiro 2015.

${ }^{24}$ Field also thinks our judgments about validity would be "somewhat nuanced" in these circumstances (Field 2015, p. 61).

\section{References}

Adams, V. W. (1998). A Primer of Probability Logic. (Stanford: CSLI Publications)

Beall, J.C. and Restall, G. (2006). Logical Pluralism. (Oxford: Oxford University Press)

Berker, S. (2013). Epistemic Teleology and the Separateness of Propositions. The Philosophical Review 122, 337-393.

Broome, J. (2013). Rationality Through Reasoning. (Chichester: Wiley Blackwell)

Caret, C. R. (2017). The Collapse of Logical Pluralism has been Greatly Exaggerated. Erkenntnis 82, 739-760.

Conant, J. (1991). 'The Search for Logically Alien Thought: Descartes, Kant, Frege, and the Tractatus'. Philosophical Topics 20, 115-180.

Cuneo, T. (2007). The Normative Web. (Oxford: Oxford University Press)

Field, H. (2009a). What is the Normative Role of Logic?” Proceedings of the Aristotelian Society, Supplementary Volumes 83, 251-268.

Field, H. (2009b). Pluralism in Logic. Review of Symbolic Logic 2, 342-359. 
Field, H. (2015). What is Logical Validity? (In Caret, C.R. and Hjortland, O. T. (eds). Foundations of Logical Consequence. Oxford: Oxford University Press.)

Frege, G. (1918). Der Gedanke: Eine logische Untersuchung. Beiträge zur Philosophie des deutschen Idealismus, $58-77$.

Frege, G. (1979). Posthumous Writings. (Chicago: The University of Chicago Press)

Hájek, A. (2012). Interpretations of Probability. (In Zalta, E. N. (ed.), The Stanford Encyclopedia of Philosophy. Retrieved June 62019 from https://plato.stanford.edu/archives/win2012/entries/probability-interpret/)

Harman, G. (1986). Change in View: Principles of Reasoning. (Cambridge, MA: MIT Press)

Harman, G. (2009). Field on the Normative Role of Logic. Proceedings of the Aristotelian Society 109, 333-335.

Kolodny, N. (2005). Why be Rational? Mind 114, 509-563.

MacFarlane, J. (2002). Frege, Kant, and the Logic in Logicism. The Philosophical Review 111, $25-65$.

MacFarlane, J. (2004). In what sense (if any) is logic normative for thought? (Paper presented at the Central Division APA symposium on the normativity of logic.)

Mackie, J. (1977). Ethics: Inventing Right and Wrong. (London: Penguin Books)

McSweeney, M. M. (2017). Following logical realism where it leads. Philosophical Studies (in press). DOI $10.1007 / \mathrm{s} 11098-017-1008-0$

Mezzadri, D. (2015). Frege on the Normativity and Constitutivity of Logic for Thought II. Philosophy Compass $10,592-600$

Murzi, J. \& Shapiro, L. (2015). Validity and truth-preservation. (In: Achourioti T., Galinon H., Martínez Fernández J., Fujimoto K. (eds). Unifying the Philosophy of Truth. Dordrecht: Springer.)

Nagel, T. (1986). The View From Nowhere. (Oxford: Oxford University Press)

Papineau, D. (1999). Normativity and judgment. Proceedings of the Aristotelian Society, Supplementary Volumes, 73, 17-43.

Prichard, H. A. (1912). Does Moral Philosophy Rest on a Mistake? Mind 21, 21-37.

Priest, G. (2006). Doubt Truth to be a Liar. (Oxford: Oxford University Press)

Reisner, A. (2011). Is there reason to be theoretically rational? (In Reisner, A. \& Steglich-Petersen, A. (eds.) Reasons for Belief. Cambridge: Cambridge University Press.)

Resnik, M. D. (1985). Logic: Normative or descriptive? The ethics of belief or a branch of psychology? Philosophy of Science 52, 221-238.

Ross. W. D. (1930). The Right and the Good. (Oxford: Oxford University Press) 
Russell, G. (2017). Logic isn’t normative. Inquiry (in press). DOI 10.1080/0020174X.2017.1372305

Shafer-Landau, R. (2003). Moral Realism. (Oxford: Oxford University Press)

Singer, D. J. (2018). How to be an Epistemic Consequentialist. Philosophical Quartely 68, 580-602.

Steinberger, F. (2017). The Normative Status of Logic. (In Zalta, E. N. (ed.), The Stanford Encyclopedia of Philosophy. Retrieved June 62019 from https://plato.stanford.edu/archives/spr2017/entries/logic-normative/)

Steinberger, F. (2019). Three ways in which logic might be normative. Journal of Philosophy 116, 5-31.

Sylvan, K. (2018). Veritism Unswamped. Mind 127, 381-435.

Taschek, W. W. (2008). Truth, Assertion, and the Horizontal: Frege on 'The Essence of Logic'. Mind 117, 375401.

Wedgwood, R. (2002). The aim of belief. Philosophical Perspectives 16, 267-297. 